\title{
Operation analysis of leakage protection including auxiliary current source operating as series ohmmeter systems
}

\begin{abstract}
This paper outlines issues related to the features of the leakage protections, especially the resistance of central leakage protections provided with the auxiliary current source to network interferences. It reveals susceptibility of the central leakage protections to this type of interferences (especially in the case of usage current sources of small rated currents).
\end{abstract}

Key words: central leakage protection $(C Z U)$, leakage resistance, capacitance to earth, protective diode barrier

\section{INTRODUCTION}

In underground mine networks, as means that monitor insulation condition of network, the below-mentioned items are applied: leakage protection, interlock protection, as well as systems applied to control earthing continuity. Leakage protection control the network insulation condition that operates live. In the case of a decrease, leakage resistance $R_{d}$ below the threshold value (concordant to specified standard $[2,3]$ ), the task of such protection is to switch off (or to signal) a damaged fragment of a network. Leakage protection solutions available on the market may be divided into two groups: protection based on a constant auxiliary source as well as protection based on an alternative auxiliary source. The majority leakage protection available on the market are based on a constant/solid auxiliary source. Both types of protection are based on direct auxiliary voltage, and protection based on a direct auxiliary current are available. Regardless of the auxiliary source type applied, solutions that work in the arrangement of a series-connected ohmmeter or in arrangement of a parallel-connected ohmmeter are available.

Current $i_{p}$ is a measured value in the protection based on direct auxiliary voltage working as a series- -connected ohmmeter (Fig. 1a). Information related to this current may be obtained on the basis of voltage drop $u_{b}$ along shunt $R_{b}$. Then, the value of leakage resistance $R_{d}$ is described using the following dependence:

$$
R_{d}=\frac{E_{p}}{I_{p}}-\left(R_{p}^{\prime}+R_{p}^{\prime \prime}+R_{b}\right)
$$

where:

$$
\begin{aligned}
R_{d}- & \text { value of leakage resistance }[\mathrm{W}], \\
E_{p}- & \text { value of auxiliary source voltage of leakage } \\
& \text { protection }[\mathrm{V}], \\
I_{p}- & \text { average value of measuring current of } \\
& \text { leakage protection }[\mathrm{A}], \\
R_{p}= & R_{p}^{\prime}+R_{p}^{\prime \prime}-\text { value of equivalent series resis- } \\
& \text { tance of leakage protection }[\mathrm{W}] .
\end{aligned}
$$

Moreover, the diagram presented in Figure 1a takes into account other items connected with leakage protection: filtering elements (capacities $C_{A}$ and $C_{B}$ ), series inductance $L_{p}$, as well as remaining elements connected with mains (equivalent capacitance to earth $C_{D}$ and equivalent interference voltage $U_{s}$ ).

In the alternative solution (Fig. 1b), leakage protection is based on direct auxiliary current $I_{p}$, and voltage $u_{z}$ is a measured value across the supply terminals. 
a)

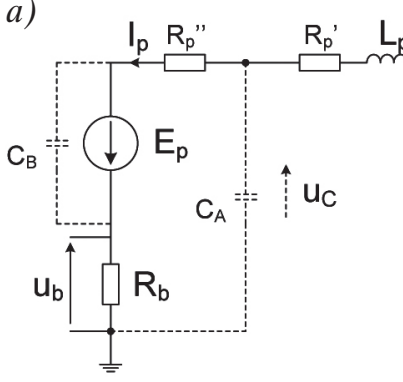

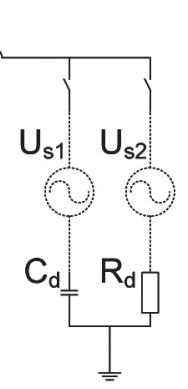

b)

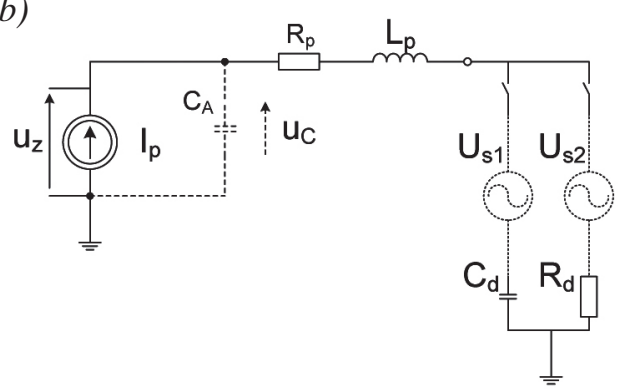

Fig. 1. Simplified equivalent circuit diagram of leakage protection operating in arrangement of series-connected ohmmeter based on: a) direct auxiliary voltage; b) direct auxiliary current

The example protection based on direct auxiliary current working in arrangement of a series-connected ohmmeter is PM-2 protection [4]. Then, the network insulation condition is described by dependence [1]:

$$
R_{d}=\frac{U_{z}}{I_{p}}-R_{p}
$$

where:

$U_{z}$ - average value of measuring voltage of leakage protection [V],

$I_{p}$ - value of auxiliary current of leakage protection $[\mathrm{A}]$.

Investigations focusing on leakage protection features based on direct auxiliary current that operate as a series-connected ohmmeter as well as the susceptibility of this type of protection to factors that interfere with their operation as related to valid mining standards shall be presented in the current paper.

\section{RESEARCH MODEL}

It was assumed that the simplified diagram is to be assumed for simulation tests that take into consideration the most-important elements of the leakage protection alone based on direct auxiliary current and the most-important parameters of the electric network as well. The assumption of such a solution allows us to watch the behavior of the leakage protection: while switching on to the network, while appearing resistance changes and capacitance to earth in network under examination, as well as interference created under transient states. An analysis of the results obtained shall allow us to estimate the correctness of the reaction of such types of protection towards the situations that occurred. Their resistance to interference that appears in these states could be determined as well. Results of the examinations performed shall allow us to estimate the usability of the leakage protection based on direct auxiliary current to operate in the low voltage networks of mines.

The simplified equivalent circuit diagram of leakage protection based on direct auxiliary current is presented in Figure 2. This diagram distinguishes the part representing the most-important element of the leakage protection (CZU) as well as the part representing the most-important equivalent parameters of the network under examination (ZPS).

Leakage protection contains auxiliary current source $I_{p}$, resistor and series impedance coil $\left(R_{p}, L_{p}\right)$, filtering capacitor $C_{A}$, as well as a voltage limiter in the form of a diode protective barrier (DBO) that contains resistors $R_{b 1}$ and $R_{b 2}$ as well as a set of stabilization diodes (Zener diodes) $D_{z 1}$ and $D_{z 2}$. A network in which different failure states occur is represented by equivalent resistance and capacitance to earth $\left(R_{d}, C_{d}\right)$ as well as equivalent interference voltage $U_{s}$.

Moreover, the diagram includes the following:

- $u_{z}$ - temporary value of measuring voltage of leakage protection [V],

- $u_{1}-$ temporary equivalent value of input voltage of the protection [V].

Network insulation condition is then described by the dependence as follows:

$$
R_{d}=\frac{U_{z}}{I_{p}}-\left(R_{p}+R_{b 1}+R_{b 2}\right)
$$

Voltage sensitivity of leakage resistance measure:

$$
\Delta U_{z}=\Delta R_{d} I_{p}
$$

The relationship (4) shows that increase of the measured voltage exhibits linear dependence on increase of the leakage resistance $R_{d}$ and on the increase of the magnitude of the auxiliary current $I_{p}$. 


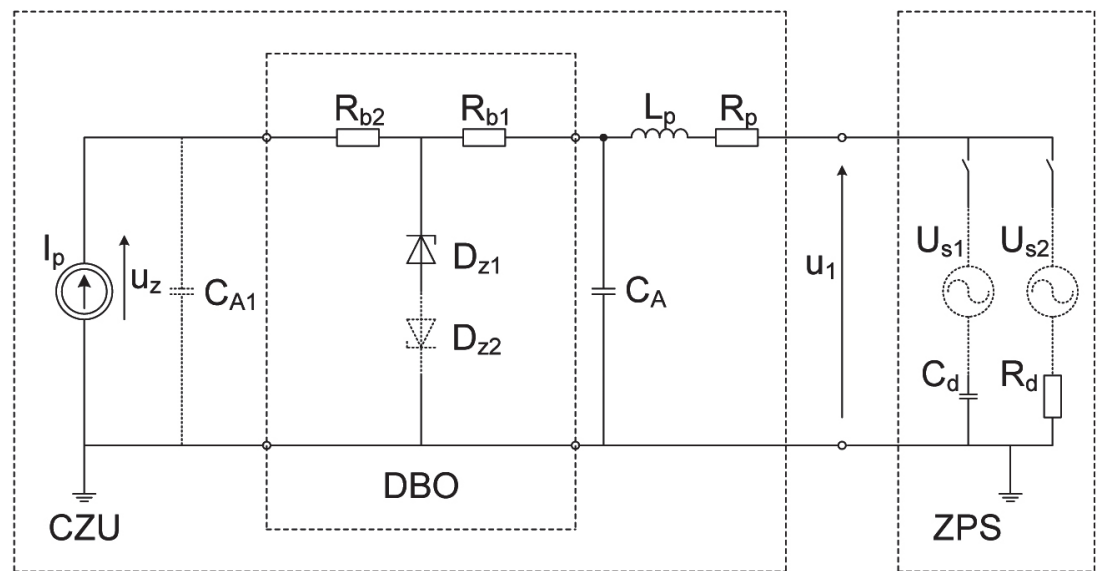

Fig. 2. Simplified equivalent circuit diagram of leakage protection based on direct auxiliary current (series-connected ohmmeter arrangement) assumed for simulation examinations

\section{SIMULATION EXAMINATIONS}

Based on the diagram presented in Figure 2, a series of simulation examinations were accomplished using TCAD simulation software. The following were assumed: $U_{s}=500 \mathrm{~V}, R_{p}=4 \mathrm{k} \Omega, R_{b 1}=10 \mathrm{k} \Omega$, $R_{b 2}=1.2 \mathrm{k} \Omega, C_{A}=3 \mu \mathrm{F}, L_{p}=340 \mathrm{H}, I_{p}=0.2 \mathrm{~mA}$. The first case (Fig. 3) presents protection operation while it is symmetrically actuated at instant $t=0.2 \mathrm{~s}$ to the wide area network $\left(C_{d}=3 \mu \mathrm{F}\right)$ and then the occurrence of a three-phase symmetrical decrease of leakage resistance $R_{d}$ to value $15 \mathrm{k} \Omega$ (at instant $t=0.8 \mathrm{~s}$ ). For the assumed parameters, the value of the threshold voltage (that corresponds to the threshold resistance $15 \mathrm{k} \Omega$ for network $500 \mathrm{~V}$ ) below which the actuation of leakage protection should follow, is about $6 \mathrm{~V}$. During the switching on of the protection to the network, oscillations shall appear in measurement voltage $u_{z}$ generated by the resonance system $\left(L_{p}, C_{A}, C_{d}, R_{p}, R_{d}\right)$.

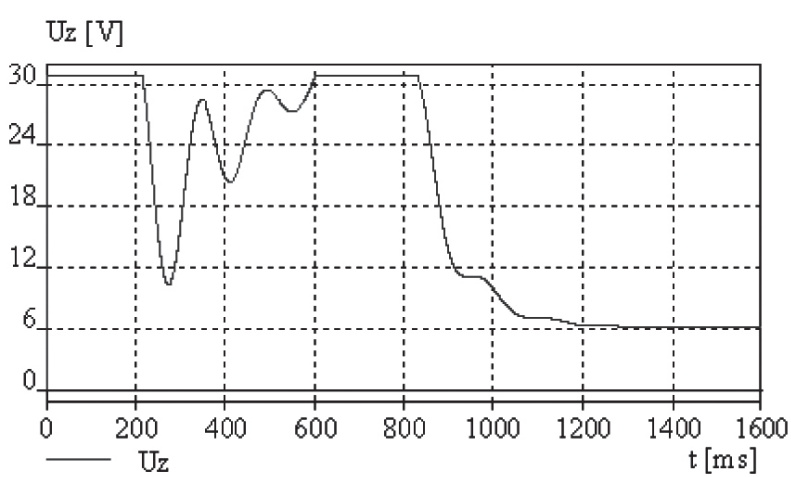

Fig. 3. Symmetric switching on leakage protection $(t=0.2 s)$ and symmetric three-phase decrease of earth resistance to value of $R_{d}=15 \mathrm{~kW}(t=0.8 \mathrm{~s})$ in wide area network $\left(C_{d}=3 \mu F\right)$
In the network under consideration during the switching on of the protection to the network, cases of unnecessary actuations of leakage protection should not occur due to the reason that measured voltage $u_{z}$ does not reach a value less than the threshold value $(6 \mathrm{~V})$. However, such problems may appear in the case of switching on this type of leakage protection to a $1000 \mathrm{~V}$ network [5].

Simulation tests proved that the measurement voltage reaches the expected value.

The next two simulations (Fig. 4a, b) relate to connecting the leakage protection to wide area network $\left(C_{d}=3 \mu \mathrm{F}\right)$ at instant $t=0.2 \mathrm{~s}$ as well as the occurrence of a single-phase decrease of leakage resistance to value $R_{d}=1 \mathrm{k} \Omega$ at instant $t=0.8 \mathrm{~s}$. The difference between the simulated systems resided in applying the diode protection barrier that contained one or two push-pull switched-on stabilization diodes (Fig. 2). The use of one stabilization diode contributes to a decrease in the interference voltage in measurement voltage $U_{z}$ due to the restriction of the minimum value of the measurement voltage to the diode forward voltage (Fig. 4a). The use of two stabilization diodes causes an increase in the resonance component (that results from the existence of an oscillation circuit) in measurement voltage $u_{z}$ (Fig. $4 \mathrm{~b}$ ).

An increase of the earth resistance to the set value of leakage protection $\left(R_{d}=15 \mathrm{k} \Omega\right)$ in mine wide area network $\left(C_{d}=3 \mu \mathrm{F}\right)$ limits the peak-to-peak value of the variable component (of network frequency). Under these conditions, there is no problem with temporary values of measuring voltage $u_{z}$ appearing that are smaller than zero. This problem also does not appear in the situation when the protection operates 
a)

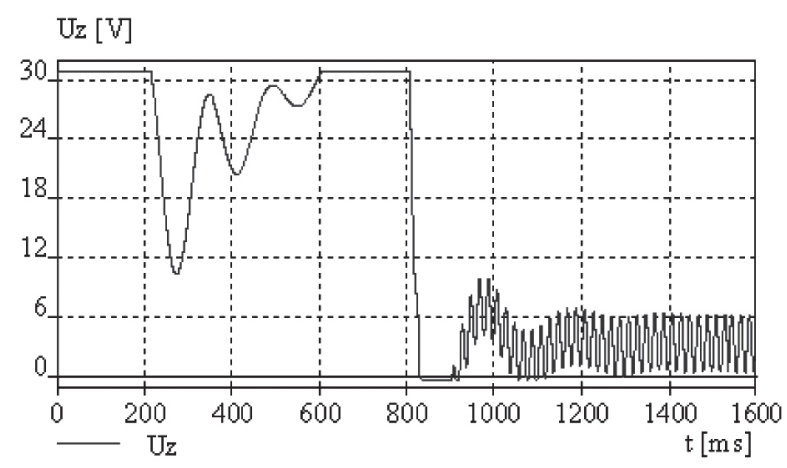

b)

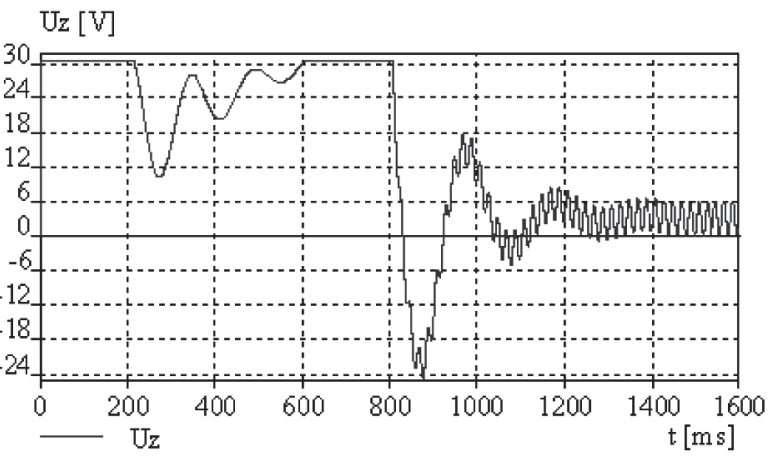

Fig. 4. Symmetric switching on leakage protection $(t=0.2 s)$ and single-phase decrease of earth resistance to value $R_{d}=1 \mathrm{~kW}(t=0.8 \mathrm{~s})$ in wide area network $\left(C_{d}=3 \mu \mathrm{F}\right):$ a) with one stabilization diode;

b) with two stabilization diodes

in the short area network that is at small capacity to earth $\left(C_{d}=30 \mathrm{nF}\right)$. Such a situation is illustrated by the course of the measuring voltage presented in Figure 5.

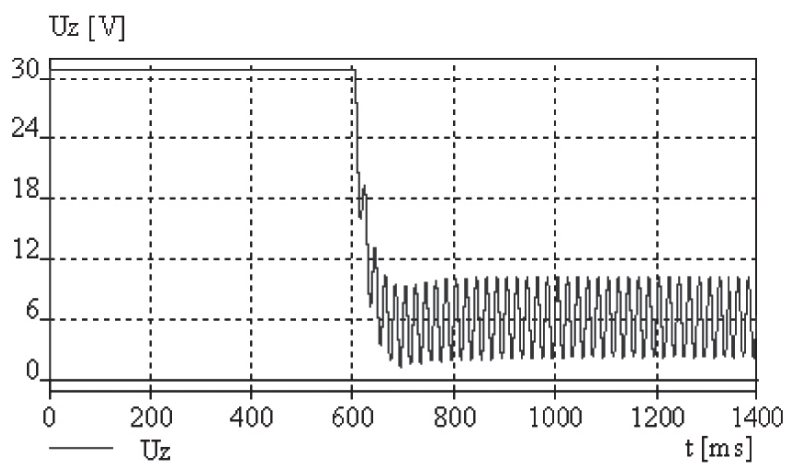

Fig. 5. Symmetric switching on leakage protection $(t=0.2 s)$ and single-phase decrease of earth resistance to value $R_{d}=15 \mathrm{~kW}(t=0.6 \mathrm{~s})$ in short area network $\left(C_{d}=30 n F\right)$ provided with one stabilization diode

a)

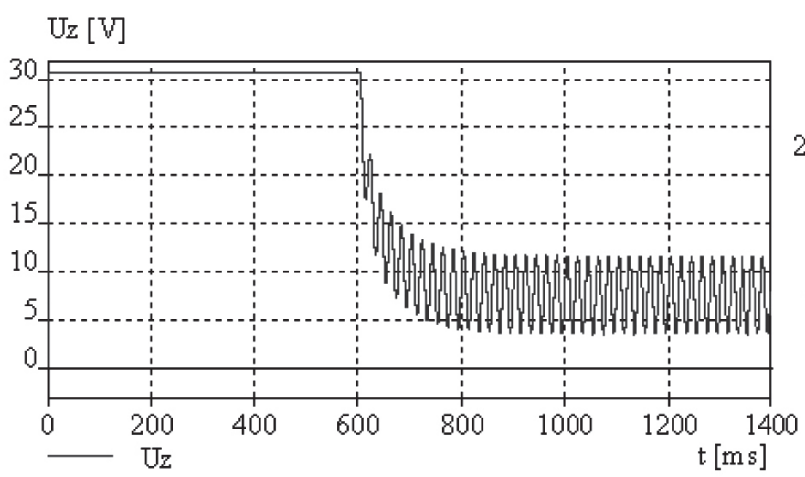

Oscillations do not appear after the actuation of the leakage protection to the network in the courses of measurement voltages $u_{z}$. However, at small capacitances to earth $\left(C_{d}=30 \mathrm{nF}\right)$ after a decrease of earth resistance value $R_{d}$ up to $15 \mathrm{k} \Omega$, the peak-to-peak value of the measuring voltage course increases.

An increase of the earth resistance to $150 \%$ of threshold value $\left(R_{d}=22.5 \mathrm{k} \Omega\right)$ causes a growth in the average value of the measurement voltage (as related to the threshold voltage value of the leakage protection actuation). Under these conditions, no problem exists related to a decrease in the temporary values of the measurement voltage below zero (Fig. 6a, b). Simultaneously, the temporary value of the measurement voltage achieves values smaller than the threshold value during a specified time. Hence, under these conditions, it is additionally necessary to filter (analogue or digital) the interference voltage in order to eliminate the possibility of incorrect protection actuation.

b)

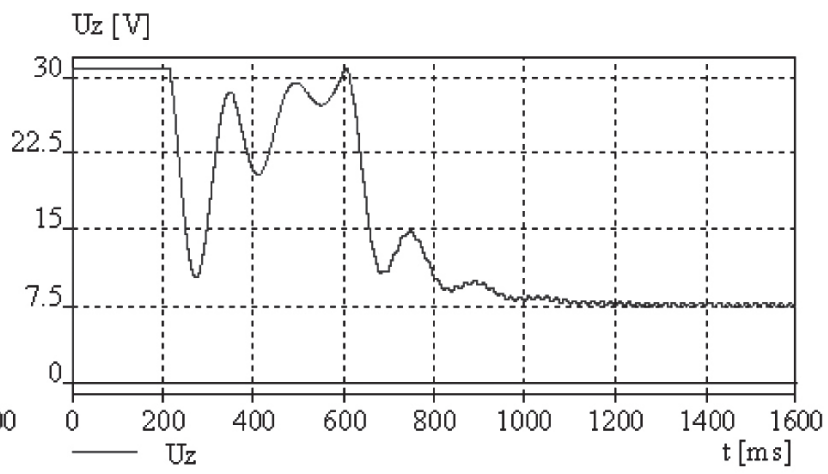

Fig. 6. Symmetric switching on leakage protection $(t=0.2 \mathrm{~s})$ and single-phase decrease of earth resistance to value of $R_{d}=22.5 \mathrm{~kW}(t=0.6 \mathrm{~s}):$ a) in short area network $\left(C_{d}=30 \mathrm{nF}\right)$;

b) in wide area network $\left(C_{d}=3 \mu F\right)$ 
According to the PN-G-42040 standard [3], decreasing earth resistance $R_{d}$ to $150 \%$ of the threshold value of the leakage protection actuation (for $500 \mathrm{~V}$ network, $R_{d}=22.5 \mathrm{k} \Omega$ ) at maximum capacitance to earth $C_{d}(3 \mu \mathrm{F})$ should not cause its actuation. From Figure $6 \mathrm{~b}$ results that the temporary values of measurement voltage $u_{z}$ are always greater than $6 \mathrm{~V}$. Thus, the above-mentioned requirement of the standard will be fulfilled.

The PN-G-42040 standard [3] provides that, in the case of switching on (switching off) the asymmetrical line of phase capacity equal to half of the maximum of earth phase capacity $(0.5 \mu \mathrm{F})$, leakage protection actuation should not occur. The received course of measurement voltage $u_{z}$ (Fig. 7) suggests that, under the above-mentioned conditions, an incorrect actuation of protection should not occur. Additionally, the use of suitably large capacity $C_{A}$ causes that the minimum value of the measurement voltage is considerably greater than the threshold value.

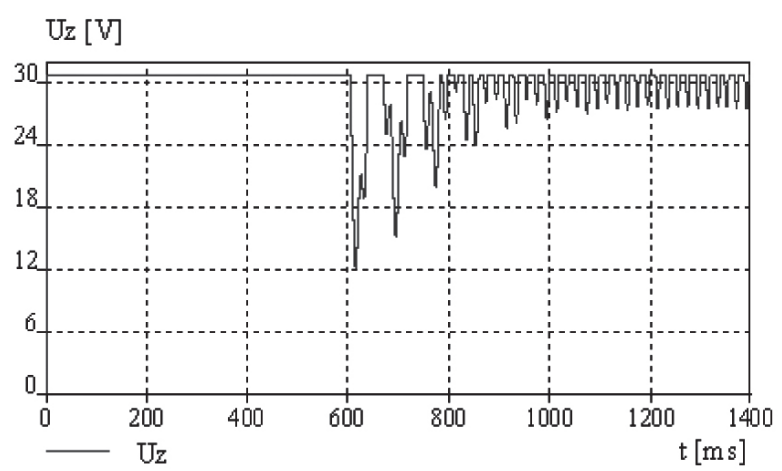

Fig. 7. Switching on $(t=0.6 \mathrm{~s})$ of a half of maximum single-phase capacitance to earth $\left(C_{d}=0.5 \mu F\right)$ to leakage protection provided with one stabilization diode

a)

$\mathrm{Uz}[\mathrm{V}]$

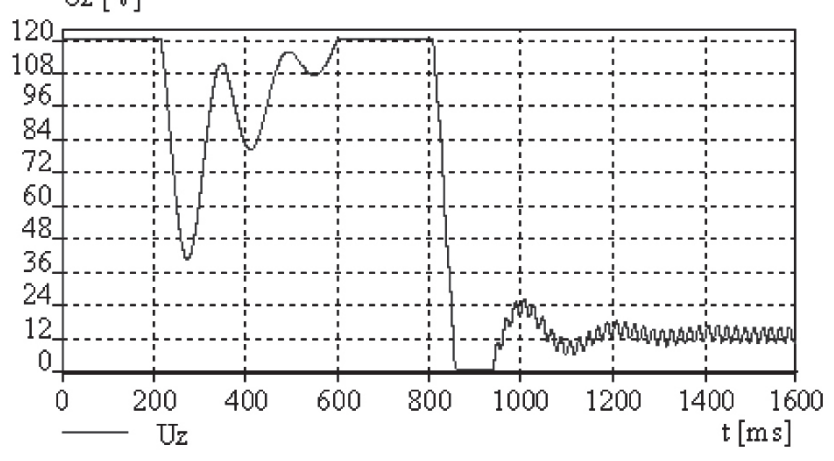

Sensitivity of the leakage protection to the interference component also depends on the value of the current of auxiliary source $I_{p}$. An increase in current value $I_{p}$ contributes to a decrease in the relative share of the interference component in measurement voltage $u_{z}$ (Figs. 8a, 8b), both in the case of a decrease of earth resistance to a value of $1 \mathrm{k} \Omega$ and up to a value of $15 \mathrm{k} \Omega$. The use of leakage protection of larger auxiliary current $I_{p}$ requires the use of a series connection of stabilization diodes.

According to the standard PN-G-42040 [3] in networks of voltage up to $500 \mathrm{~V}$ (inclusive), the actuation time of leakage protection (in the case when earth resistance decreases to a value of $R_{d}=1 \mathrm{k} \Omega$ ) should not be longer than $0.1 \mathrm{~s}$. The reaction time of the leakage protection to a disturbance that appears in the measuring system depends first of all on an instant when this disturbance appears as related to the temporary voltage values of the mains. Such a situation is illustrated by the course of the measuring voltage presented in Figure 9. Depending on the instant when the disturbance appears, the initial phase of equivalent disturbing voltage $\varphi$ changes. The delay caused by the moment when the disturbance appears in the measuring circuit achieves the largest values in the case when the initial phase of the equivalent disturbing voltage equals $\varphi=0^{\circ}$ (Fig. 9b), whereas at angle $\varphi=180^{\circ}$, the delay of the reaction of the leakage protection to the formed disturbance is the shortest one (Fig. 9a). This delay equals about $50 \mathrm{~ms}$ under the most-unfavorable conditions. Thus, it seems that, in the case of the $500 \mathrm{~V}$ network, the protection actuation time (being a reaction to the decrease of the earth resistance to value $R_{d}=1 \mathrm{k} \Omega$ ) should be a shorter than the $100 \mathrm{~ms}$ required. Larger problems regarding the

b)

$\mathrm{Uz}[\mathrm{V}]$

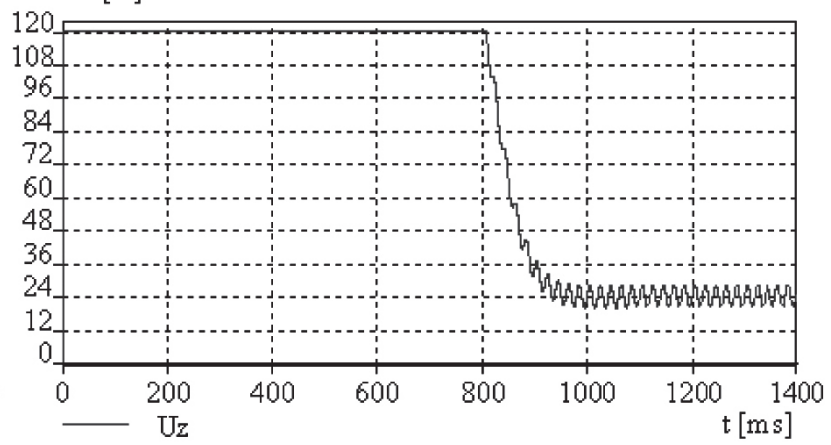

Fig. 8. Symmetric switching on $(t=0.2 \mathrm{~s})$ of leakage protection operating with $I_{p}=1 \mathrm{~mA}$ and in arrangement with one stabilization diode, where at instant $t=0.8 \mathrm{~s}$, single-phase decrease of earth resistance occurred to: a) value $R_{d}=1 \mathrm{~kW}$ in wide area network $\left.\left(C_{d}=3 \mu \mathrm{F}\right) ; b\right)$ value $R_{d}=15 \mathrm{~kW}(t=0.8 \mathrm{~s})$ in short area network $\left(C_{d}=30 \mathrm{nF}\right)$ 
a)

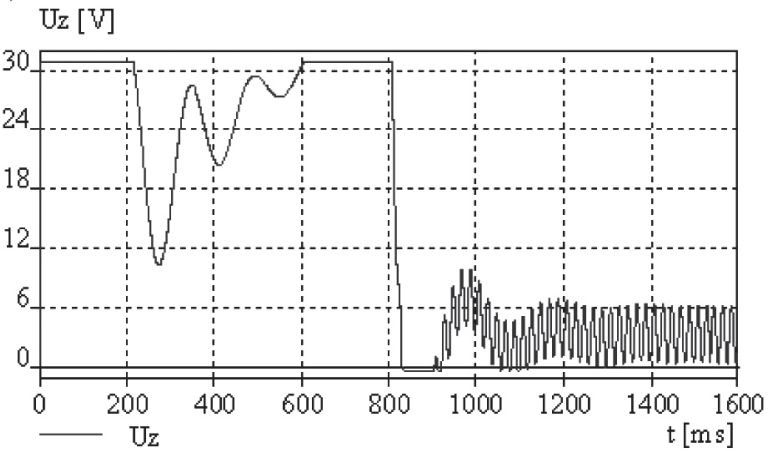

b)

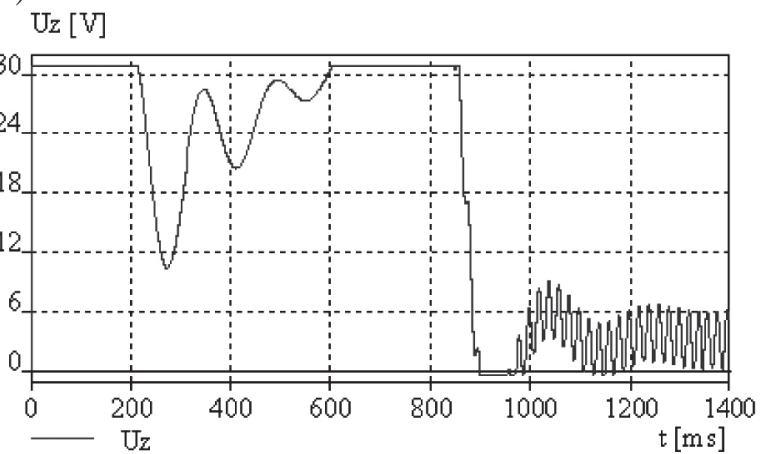

Fig. 9. Symmetric switching on leakage protection $(t=0.2 \mathrm{~s})$ and single-phase decrease of earth resistance to value $R_{d}=1 \mathrm{~kW}(t=0.8 \mathrm{~s})$ in wide area network $\left(C_{d}=3 \mu \mathrm{F}\right)$ provided with one stabilization diode and initial phase of equivalent disturbance voltage $u_{s}:$ a) $\varphi=180^{\circ}$;b) $\varphi=0^{\circ}$

meeting of this point of the standard can appear in the case of operation of this type of protection in $1000 \mathrm{~V}$ networks [5].

Besides the constant component, the variable steady component and transient component appear in the presented courses of measurement voltages. The parameters of the variable components (frequency, amplitude, attenuation) depend on network parameters $\left(R_{d}, C_{d}, U_{s}\right)$ as well as on leakage protection parameters $\left(L_{p}, R_{p}, R_{b}, C_{A}\right)$. The spot to where filter capacitor (or capacitors) $C_{A}$ in the measurement system is (are) connected has a significant effect on the oscillation amplitude of the variable component. Solutions in which condensers were applied of a total capacity of $C_{A}=3 \mu \mathrm{F}$ are illustrated by the courses of measurement voltage $u_{z}$ in Figure 10 . In the first case (Fig. 10a), one filtering capacitor was used across the input of the protective barrier diode, whereas in the second case (Fig. 10b), two filtering capacitors were used: one across output $\left(C_{A 1}\right)$, and the second

a)

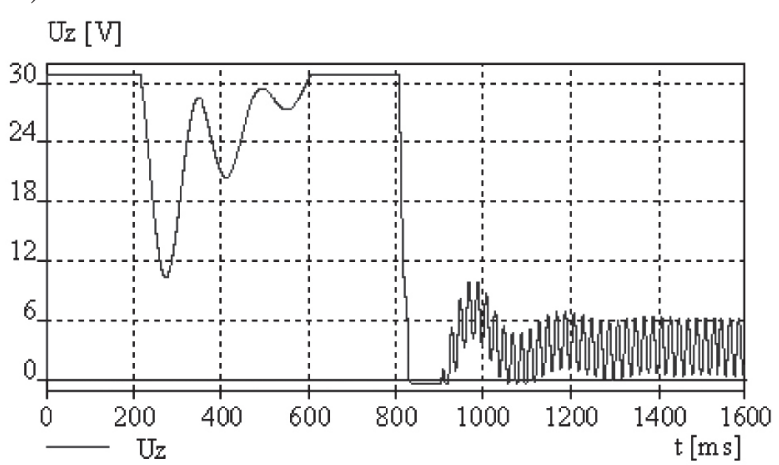

across input $\left(C_{A}\right)$ of the protective barrier diode. The results of the simulation received indicate that the solution in which two filtering capacitors (Fig. 10b) were applied give considerably better effects of attenuation in the variable component in the measurement voltage.

\section{SUMMARY}

This paper focused on the susceptibility of leakage protection based on direct auxiliary current $I_{p}$, to disturbances appearing in the network as a result of a decrease of earth resistance and during connection procedures.

The conducted simulating investigations showed that, during the switching on of the leakage protection to the network, a disturbance voltage appears whose value depends on the value of the capacitance to the b)

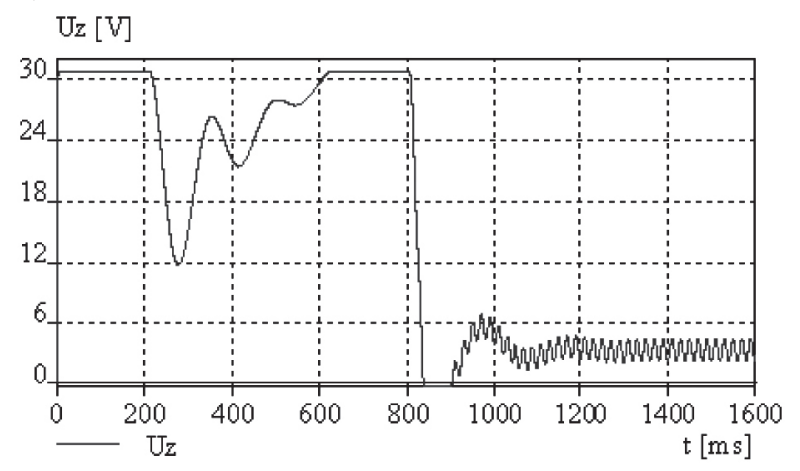

Fig. 10. Symmetric switching on leakage protection $(t=0.2 \mathrm{~s})$ and single-phase decrease of earth resistance to value $R_{d}=1 \mathrm{~kW}(t=0.8 \mathrm{~s})$ in wide area network $\left(C_{d}=3 \mathrm{mF}\right)$ provided with one stabilization diode for $\varphi=180^{\circ}$ : a) with one capacitor $C_{A}=3 \mu F$ across input of diode barrier; b) with two capacitors $C_{A 1}=1 \mu F$ across output of measurement system and $C_{A}=2 \mathrm{mF}$ across input of diode barrier 
earth of network $C_{d}$. In the case of wide area networks $\left(C_{d}=3 \mu \mathrm{F}\right)$, this appears during the course of measuring voltage $u_{z}$ in the form of an oscillation transient state. In effect, measurement voltage $u_{z}$ may reach smaller values than the threshold voltage. In the case of $500 \mathrm{~V}$ networks, the simulation examination results suggest that such problems should not appear (for $R_{d}=15 \mathrm{k} \Omega$, the value of the threshold voltage equals about $6 \mathrm{~V}-$ Fig. 3), but they may appear when leakage protection operates on $1000 \mathrm{~V}$ networks [5]. The appearance of such a situation could cause the unnecessary actuation of leakage protection. The discussed disturbance depends on the equivalent value of the capacitance to the earth of the network, and in the case of short area networks $\left(C_{d}=30 \mathrm{nF}\right)$, one does not observe any significant changes in the measurement voltage course during the connection procedure. Thus, leakage protection working in short area networks has less susceptibility to cases of the unnecessary actuation of leakage protection as a result of connection disturbances.

The values of the capacitances to earth $C_{d}$ may also influence the disturbance component course in measurement voltage $u_{z}$, which appears during a decrease in earth resistance $R_{d}$. Short networks (of small capacitance to earth $C_{d}$ ) influence the course of measurement voltage particularly unfavorably. As it was proven, disturbance voltages of relatively large amplitudes appear in this course. Application of leakage protection based on a protective diode barrier with one stabilization diode may lead to incorrectly (overestimated) determining the value of earth resistance $R_{d}$ [5]. Such a problem may appear mainly in $1000 \mathrm{~V}$ networks. In $500 \mathrm{~V}$ networks, this type of problem - within the most interesting range of values of earth resistance $R_{d}\left(R_{d}=15 \div 22.5 \mathrm{k} \Omega\right)$ - does not exist from a measurement point of view (due to the valid standards) (Figs. 5, 6).

The conducted examinations proved that leakage protection based on a larger auxiliary current $(0.8 \mathrm{~mA})$ were featured with a greater resistance to disturbances (Figs. 9a, b). An increase of auxiliary current value $I_{p}$ allowed the minimum temporary value of measurement voltage $u_{z}$ (at threshold resistance $R_{d}=15 \mathrm{k} \Omega$ ) to increase (Fig. 9b); thus, to avoid a situation in which an overestimation of the measurement of earth resistance value $R_{d}$ (for the situation in which measurement voltage $u_{z}$ would achieve negative values) would occur.
Leakage protection in $500 \mathrm{~V}$ networks are less-susceptible to disturbances in the measurement circuit (resulting from connection procedures and network disturbances), which could lead to their incorrect actuation (Figs. 3, 5, 7). These types of disturbances may, however, influence the correct functions of protection operating on $1000 \mathrm{~V}$ networks (time periods appear in the course of the measurement voltage when this voltage is smaller than the threshold voltage of the leakage protection actuation) [5]. A limitation of the amplitudes of the variable component in the course of measurement voltage may be additionally reached using two filtering capacitors: across the input and output of the protective diode barrier (Fig. 10).

Three aspects of the operation concordance of leakage protection to mining standard PN-G-42040 [3] were analyzed:

1) Switching on the earth resistance of a value 1.5 times greater than the value of the threshold resistance for short area networks. The conducted simulations (Fig. 6a) show that unnecessary actuations of leakage protection should not appear. No problem should appear with meeting the requirement of this section of the standard.

2) Switching on earth resistance of a value 1.5 times greater than the value of the threshold resistance for mining wide area networks. Conducted simulations (Fig. 6b) show that no problem should appear with meeting the requirement of this section of the standard.

3) The switching on/switching - off the half of the maximum phase capacitance to earth, at infinitely large resistance of the network insulation of the network $\left(R_{d}=8\right)$. The simulation results (Fig. 7) show that no problem should appear with meeting the requirement of this section of the standard.

The aspects of operation presented in this paper of leakage protection with an auxiliary current source show that no difficulties should appear to achieve the protection actuation time required by standard [3] (for the case of decreasing earth resistance in one of the phases to a value of $1 \mathrm{k} \Omega$, the required time of protection actuation for a $500 \mathrm{~V}$ network should be shorter than $0.1 \mathrm{~s}$ ) with a large resistance to connection disturbances at the same time. However, such problems may appear in the case of leakage protection operating in $1000 \mathrm{~V}$ networks (the required time for protection actuation has to be shorter than $70 \mathrm{~ms}$ ). 


\section{References}

[1] Marek A.: Wybrane zagadnienia ochrony ziemnozwarciowej w sieciach dołowych, "Mechanizacja i Automatyzacja Górnictwa" 2012, 1: 13-20.

[2] European Standard EN 61557-8: 2015 Electric safety in low voltage power grids of alternative voltages $1 \mathrm{kV}$ and direct voltages up to $1.5 \mathrm{kV}$-Devices provided to inspect, measure or monitor the protection means. Part 8: Devices to monitor insulation condition in IT networks.

[3] Polska Norma PN-G-42040: Środki ochronne i zabezpieczajace $w$ elektroenergetyce kopalnianej. Zabezpieczenia uptywowe. Wymagania i badania, 1996.

[4] Przekaźnik mikroprocesorowy sterowniczo-zabezpieczeniowy tури PM-2 - Instrukcja obsługi, Invertim, Otwock Mały 2013
[5] Marek A.: Wybrane zagadnienia centralnych zabezpieczeń upływowych z pomocniczym źródtem prądowym, EMTECH, Katowice 2014: 82-91.

ADAM MAREK, Ph.D., Eng. Department of Electrical Engineering and Industrial Automation

Faculty of Mining and Geology

Silesian University of Technology ul. Akademicka 2, 44-100 Gliwice, Poland Adam.Marek@polsl.pl 